\title{
On the Narrative of Ernest Koliqi - The Role of Detail in Psychological Catharsis
}

\author{
Irena Alimerko \\ PhD, "Ismail Qemali" University, Vlorë, Albania \\ Alisa Velaj \\ $\mathrm{PhD}$, "Aleksandër Moisiu" University, Durrës, Albania
}

\begin{abstract}
It is the detail that enables the crossing from one time to another one, from one state to another inside the narrative of Ernest Koliqi. Let's look more concretely, through the analysis of the stories, how this detail doesn't only make shifts of times and states, but overcoming is exactly the "boiling point" of each story, the station where are overthrown all illusion or "real meaningfulness", which can be created into the reader before the sudden arrival of this detail. The permutations of situations do not necessarily result in shifts of time, while the changes of the time necessarily contain changes into the situations. To look at these metamorphoses, we are lighting on the stories "Did I leave it to you?", "Welter", "Moon of blood", "Little personage" and "It was found behind the bush". The story entitled "Welter "has on the focus a sharp social situation, which inevitably leads to the degeneration of the moral character of the mother and daughter, Sila and Lina. The story entitled "Little personage" chooses as the name of the protagonist that state which has invaded his soul and mind; a real drama in front of the inability to be free, far from the handcuffs of a deeply material world, with the walled borders that do not let his dreamlike soul to breath. Another story, in which the detail immerses the protagonist in a reflective state, is also "Moon of blood". The detail of the Moon turns into a controversy over the development of the subject. At first glance, attractiveness to the moonshine simply encourages the passage or the return from time to time (bearing within the lattermost also the changes in the characters' situations) and seems to "wax the guy" the image of this detail actually appears "to wax" completely the girl.
\end{abstract}

Keywords: detail, psychological catharsis, psychological cogitations, the past and the present

\section{Introduction}

It is the detail that enables the crossing from one time to another one, from one state to another inside the narrative of Ernest Koliqi. Let's look more concretely, through the analysis of the stories, how this detail doesn't only make shifts of times and states, but overcoming is exactly the "boiling point" of each story, the station where are overthrown all illusion or "real meaningfulness", which can be created into the reader before the sudden arrival of this detail. The permutations of situations do not necessarily result in shifts of time, while the changes of the time necessarily contain changes into the situations.. When we read a text that places a value on spiritual experience and involves spiritual perception, the act of reading gives birth to spiritual experience in us. ${ }^{1}$ To look at these metamorphoses, we are lighting on the stories "Did I leave it to you?"2, "Welter"3, "Moon of blood"4, "Little personage ${ }^{5 "}$ and "It was found behind the bush"6.

We will first focused on the analysis of the first four stories, the stories "Did I leave it to you?", "Welter", "Moon of blood", "Little personage" and "It was found behind the bush" where the detail makes the overcoming from one situation to another.

In the first story, entitled "Did I leave it to you?" the details of passing a lifeless body in front of human beings that are experiencing a true idyll in the nature's bosom, which seems to last as long as eternity, causes the immediate change of

\footnotetext{
1 Stan Scott, Poetry and the Art of Meditation: Going behind the Symbols, JAEPL, Vol. 2, Winter 2005-2006, p.77.

2 Ernest Koliqi, Flags' Merchant, Publishing House Pakti, Tirana 2009, p.13-19.

3 Ibidem, p. 82-87.

4 Ibidem, p. 110-116.

5 Ibidem, p. 26-32.

6 Ibidem, p. 39-43.
} 
the mood of the characters. From a state of true happiness, they go to evocation of the feeling that one day they will no longer be, like this lifeless body. The thought of death overwhelms their minds for a few moments and is the optimism of one of the characters that returns to a less fatal state, but nevertheless, not to the first idyll.

The story entitled "Welter "has on the focus a sharp social situation, which inevitably leads to the degeneration of the moral character of the mother and daughter, Sila and Lina. The head of the family is the main cause that has led to the ruin of his wife and daughter, because he doesn't put the earned income for the material goods of the family, but for the drink and the greasy spoons' life. The family's poverty, which becomes even greater, fails to gnaw his conscience to such an extent as to quit drinking alcohol. Only after seeing the moral degeneration of the family and experiencing the sense of shame, he feels guilty of what he caused to the family. Because he know that the original sin, the one that has led the peccability of the women of his family on the path of prostitution, is just his and only his, he does not have the strength to retaliate against Sila and Lina, but wants to leave the world himself by suicide.

The concussion does not help him to become an active human being when he sees the dehumanization of his family, trying to change the wrong way and save the woman and daughter from that path. On the contrary, it gives to him light to openly reveal his inhumanity, making him to feel deeply guilty in conscience, but leaving him again a passive human being. The glass of brandy remains his companion, but if before this glass accompanied him with joyful songs, after learning of the shocking truth that he saw with his wide opened eyes, he now drink to forget what had happened to him and in at the bottom of the glass he saw the two soft eyes that condemned him. ${ }^{1}$ The wretched eyes of his daughter did not make him to change the way, even when she dropped the school because she had nothing to wear and shoe. They had not led him to any reflection, that he would be the executioner who would one day lead her family to the guillotine of destruction. The will to avoid the tragedy had never been rooted in Ndrekë Batuçi's consciousness, though he knew that the path he had followed until that moment was wrong. This makes even more inhuman the tragic turn of life of two female characters.

The downfall of the head of the family comes when he faces the truth that seemed to doubt about it in the deepest realms of consciousness. It is the detail that turns the "hangman" into a victim of the crime caused by him. The suddenness of the subject's turn point serves to bring the peculiar transformation of characters in dramatic circumstances. ${ }^{2}$ And it is precisely the detail that involves in itself the transformation, self-knowledge in relation to this itself, as in relation to other.

\section{"- My God! What is the person doing in our alley? (Detail or turning point)}

Suddenly, as a poisonous snake, a suspicion bit him into the soul. He knew one by one all the inhabitants of his alley. Their relationship with that employee was not explained...

Then ..." "3

After knowing the naked truth, his character is transformed, not in the sense of getting better, but now he undergoes the catharsis which is necessary to see him-self in the eye. Knowing the truth leaves him as passive as before knowing that he was not walking in a straight path and had no power to rule over his own defect, so the drink. The drink, from the "friend of joys", now turns into a "friend of despair". The eyes of her daughter, where he perused his guilt and the condemnation without appeal, are the ones he always sees at the end of the glass. On the other hand, the daughter's total disregard for his state of shame increases much more the dramatic essence of this story. Thus, the father's figure is nothing more than a shadow for his creation, or something in a memory. And this character is really a thing, while, even when all the possibilities for reflection have been given to him, he does not again become an active being for the sake of paternal love.

The story entitled "Little personage" chooses as the name of the protagonist that state which has invaded his soul and mind; a real drama in front of the inability to be free, far from the handcuffs of a deeply material world, with the walled borders that do not let his dreamlike soul to breath. As the turning point here is the detail or the metaphor of the sea.

"Suddenly a light inside of him: he knows: he could not wait to see the sea .... 4 " (Detail or hidden turning point which leads the human being to the reflection and change of state).

\footnotetext{
1 Ernest Koliqi, Flags' Merchant, Publishing House Pakti, Tirana 2009. p. 84.

2 Leka Ndoja, Notes on Flags' Merchant, Publishing House Pakti, Tirana 2009, p. 87.

${ }^{3}$ Ernest Koliqi, Flags' Merchant, Publishing House Pakti, Tirana 2009 f. 86.

${ }^{4}$ Ibidem, p. 30.
} 
"What grieved the son of Tef Ballstani, the merchant of Shkodra, night and day gripped in profit thoughts, was his inability to develop beyond the beautiful fairytale about the sea ...." 1 (Direct closing detail of the story).

The sea is presented here in that viewpoint that also is seen by the researcher Dhurata Shehri, so as a trend towards the West and modernity. Here we have the war between the walls, or the closure of the mountain, a child who has his father as the watchful guard and the free spirit of a child dreaming of infinite spaces, immensity, where the flights are his life and his true spirit, which the materialist merchant is unable to understand. His father's world symbolizes the closed and narrowminded orient, while the free and unprejudiced world of the child (there can be no such thing, because he is still innocent) symbolizes the occident, for which many characters of Koliqi dream about.

In a wider comprehension, the presence of the child between a closed space (real physical space) and dreaming of an infinite space (dreamy spiritual space) can also be taken as a treatment of the philosophical concept of freedom and lack of freedom, what keeps us tied like a cuff and what gives us the proper breathing to reach the limits of the impossible. The little personage undergoes a catharsis only in his own dreams, which are entirely in contradiction with reality, which makes him feel like a bird locked in a cage, at a time when the azures are widely spread in his windows of the soul. The tragic deepens when he fails to be understood by everyone in the milieu where he lives and thus remains the only free spirit; herewith the sea is just a fairytale. Not merely the narrator uses the expression "the beautiful fairytale of the sea ..."

The definition as a fairytale serves to convey the idea that the milieu where was born and raised the little personage is still far from the limits of true freedom, the emancipated world. The fact that to describe the rapport between freedom and lack of freedom is chosen for the protagonist a little child can be taken as a sharp satire of what the drama of deformation does not start when the being is shaped but since begins to understand and dream; therefore, only a nation that deals with the enlightenment of the mind from an early childhood of an individual will be able to flush away the captivity of backwardness, thus sparking the light of freedom, values and civilization.

Another story, in which the detail immerses the protagonist in a reflective state, is also "Moon of blood". On a quiet night, walking with his girlfriend along the Drin River, he sees a huge, yellow, red-spots Moon that separates him from the experiences of the moment and retrospectively turns him back into the memories of early childhood.

"- What's the matter with you? Why are you scared?

- I am not scared: I stopped to watch the Moon...

- The Moon as always...

"No," he murmured with a voice as was wasted, "see the red spots ... It's not like the usual Moon ..." 2

So, two periods have been closely replaced: the present and the past. The past is manifested through the memories of that fortunate time, when the divine curiosity arouses us in front of the simple things, of the world but full of furtiveness. ${ }^{3}$ This shift from time to time brings even the change of the mood of the protagonists, but in opposite directions.

The guy becomes a captive of the imaginations of the past and leaves the present, while the girlfriend, not being able to properly understand his experiences, tries to turn him back into the present. Explaining this misunderstanding between the two human beings, the narrator (guy) and the spectator (girlfriend), the researcher Leka Ndoja writes: "Moon of Blood" addresses the subject of love and opposing psychological meditations to the couple's lover. Blending the traditional cosmic and realistic symbolism of his wife, the atmosphere of the story goes to the mistrust of lovers. Interpretation of stains in the moon, according to the girl, foretells the non-realization of her love ". The boys are the sons of Mars (war) and the girls are the daughters of Venus (love). "4

The opposite psychological meditations are the ones that bring misunderstanding, but the theme of love, which the researcher Ndoja presents in the foreground but we think that is appeared like this only in appearance. In a more hermetic

\author{
${ }^{1}$ lbidem , p. 32 \\ 2 Ibidem, p. 110. \\ 3 ibidem , p. 115 \\ ${ }^{4}$ Leka Ndoja, Notes on Flags' Merchant, Publishing House Pakti, Tirana 2009, p. 116.
}


textual connotation, the real theme is the great love of Albanians for the denied centenarian freedom of Albanian lands. So we see that the boy remembered so much that Moon with a red stains, only for the fact that after the words of the Montenegrin old woman, spoken in 1911 (not accidentally have to be prophetic), our lands were faced with such tragedies, such as the War of Tarabulluzi, the two Balkan Wars and the First World War. Although the text does not say it openly, we should not forget the historical referent of 1913 when Albanian lands were torn apart by the Great Powers at the London Ambassadors Conference. Confessing personage, recalling childhood memories in his confession, is tortured by the idea that he is the son of those lands, which never experienced calmness by the infinite wars and lack of freedom. His childhood dreams are still alive, as the story comes to us published in 1935, when Albania was still a fragmented state after the decision taken by the Great Powers 22 years ago.

The narrative character seems even pissed off by the girlfriend's guesses about the depth of his love feelings; by failing to understand what is happening in his experiences, she foresees at the red-spotted moons (as the researcher Ndoja points out) the prescience of not realizing her love. We note throughout the text that she is overwhelmed by the fact that the story and the words of the Montenegrin babushka occurred in 1911, since the uncultivated and superstitious mentality of the milieu where was raised has nourished, among her innermost feelings, the instinct of explanation things not based on independent personal reasoning, but by stereotype behavior and unreasonable prejudices. So bearing in mind by the fiancée of the fact of breaking the Albanian lands, according to her, must be an evil omen for the future of their love.

Thus, on the one hand, we have the guy who is quite confident in his feelings, so he does not stop for long time in analysis of feelings, but simply requires a free space and perhaps a worthy converser for his intellectual experiences, while in on the other hand, we have the maid who, with her superstitious behavior, shows the nature of a being who fears not only the future, but also the moment when the guy wants to be away from her, just for a subjective meditation. Thus, the detail of the moon turns into a controversy over the development of the subject. At first glance, attractiveness to the moonshine simply encourages the passage or the return from time to time (bearing within the lattermost also the changes in the characters' situations) and seems to "wax the guy" the image of this detail actually appears "to wax" completely the girl. By inviting stillness in the mind, the lines move us into a kind of experience that spiritual teachers call meditative or contemplative $^{1}$ From another point of view, this time a psychological one, if the story will be analyzed in the field of explorations into the unknowns of the psyche, the unknown itself and the struggle with it, its exploration or invasion would come out as a native gift of the boys, while for the girls it would be said that in any exploration or unknown they seek a sense of love, thereby reinforcing the conclusion of the researcher Ndoja, that the boys are the sons of Mars (war) and the girls are the daughters of Venus (love).

\section{Refrerences}

[1] Adnan K. Abdulla, Catharsis in Literature, Indiana University, Folklore Institute, 1985.

[2] Ernest Koliqi, Flags' Merchant, Publishing House Pakti, Tirana 2009.

[3] Ernest Koliqi, Flags' Merchant, Publishing House Pakti, Tirana 2009 p. 110.

[4] Ernest Koliqi, Flags' Merchant, Publishing House Pakti, Tirana 2009 p. 115.

[5] Ernest Koliqi, Flags' Merchant, Publishing House Pakti, Tirana 2009 p. 30.

[6] Ernest Koliqi, Flags' Merchant, Publishing House Pakti, Tirana 2009 p. 32.

[7] Ernest Koliqi, Flags' Merchant, Publishing House Pakti, Tirana 2009 P. 86.

[8] Ernest Koliqi, Flags' Merchant, Publishing House Pakti, Tirana 2009, p. 110-116.

[9] Ernest Koliqi, Flags' Merchant, Publishing House Pakti, Tirana 2009, p. 26-32.

[10] Ernest Koliqi, Flags' Merchant, Publishing House Pakti, Tirana 2009, p. 82-87.

[11] Ernest Koliqi, Flags' Merchant, Publishing House Pakti, Tirana 2009, p.13-19.

\footnotetext{
${ }_{1}^{1}$ Stan Scott, Poetry and the Art of Meditation: Going behind the Symbols, JAEPL, Vol. 2, Winter 2005-2006, p.77
} 
[12] Ernest Koliqi, Flags' Merchant, Publishing House Pakti, Tirana 2009, p.13-19.

[13] Ernest Koliqi, Flags' Merchant, Publishing House Pakti, Tirana 2009. p. 84.

[14] Leka Ndoja, Notes on Flags' Merchant, Publishing House Pakti, Tirana 2000.

[15] Leka Ndoja, Notes on Flags' Merchant, Publishing House Pakti, Tirana 2009, p. 116.

[16] Leka Ndoja, Notes on Flags' Merchant, Publishing House Pakti, Tirana 2009, p. 87.

[17] Poozato, Semiotika e tekstit, ShBLU, Tiranë 2004.

[18] Stan Scott, Poetry and the Art of Meditation: Going behind the Symbols, JAEPL, Vol. 2, Winter 2005-2006

[19] Stan Scott, Poetry and the Art of Meditation: Going behind the Symbols, JAEPL, Vol. 2, Winter 2005-2006, p.77 